Research

\title{
A simulation study of the effect of post-combustion amine-based carbon-capturing integrated with solar thermal collectors for combined cycle gas power plant
}

\author{
Amir Ayyad ${ }^{1,2} \cdot$ Ayman Abbas $^{2} \cdot$ Nabil Elminshawy $^{2,3}$ \\ Received: 28 January 2021 / Accepted: 15 February 2021 \\ (C) The Author(s) 2021 OPEN
}

\begin{abstract}
Post-combustion carbon capture with solvent designed to sequestrate carbon from power plant is a promising and wellknown technology. However, a vital drawback is the reduction of the power plant output due to the energy required to separate captured $\mathrm{CO}_{2}$ from the solvent, known as a re-boiler duty. In this paper, two configurations were simulated and economically examined to mitigate the re-boiler duty and power loss from the $495 \mathrm{MW}$ West Damietta power plant, Egypt. The first approach is to increase carbon concentrations in the feed to carbon capture plant by recycling part of exhaust gas back to the combustion chamber with different ratios $(0 \%-35 \%)$, the second approach is implementing parabolic-trough solar collectors to handle the reboiler load instead of low-pressure steam extracted from the power plant. Both power and $\mathrm{CO}_{2}$ capturing plants were simulated using Aspen Hysys. Parabolic trough solar collector plant was simulated using system advisor model software. The results revealed that increasing carbon content led to a remarkable decrease in reboiler duty by up to around $20 \%$. It was also found that integrating the solar plant with thermal storage system highly improved the optimum production compared to plant without thermal storage. Carbon increase also affected the levelized cost of energy which had $1.39 \%$ reduction and $6 \%$ decrease in carbon cost of avoidance using $35 \%$ recirculation ratio.
\end{abstract}

Keywords Carbon emissions · Post-combustion capture $\cdot$ Exhaust gas recirculation $\cdot$ Solar heating $\cdot$ Combined cycle gas turbine

\section{Literature review}

The crucial issue for each nation's sustainable economic growth is energy. However, the balance of economic growth and protection of environment is always an inevitable challenge for the sustainable development of the human population worldwide. Rapid economic growth has gradually increased demand for energy in recent years, through low cost, high calorific value fossil fuels, such as coal and natural gas which are commonly used in power plants [1]. The concern is that emissions of greenhouse gases contribute to global warming, rising sea levels and other environmental effects. In 2015, countries around the world signed the Paris Agreement calling for lower $\mathrm{CO}_{2}$ emissions to slowdown the increase in average global temperature. Renewable energies are green sources that escalate with a noticeable rate [2]. However, in the near term, fossil-based fuels will be the primary selection for most energy applications. Combined cycle gas turbine (CCGT) power generation plants currently account for more than $20 \%$ of global electricity production and the efficiency

Amir Ayyad, ayaad.a@hotmail.com | 'Operations Department, Egyptian Methanex Methanol Company (EMethanex), Cairo, Egypt. ${ }^{2}$ Mechanical Engineering Department, Faculty of Engineering, The British University in Egypt, El-Shorouk City, Cairo 11837, Egypt. ${ }^{3}$ Mechanical Power Engineering Department, Faculty of Engineering, Portsaid University, Portsaid 42526, Egypt.

Discover Sustainability $\quad$ (2021) $2: 9 \quad$ | https://doi.org/10.1007/s43621-021-00018-x 
of CCGT plants can reach up to $55-60 \%[3,4]$. To reach the desired $\mathrm{CO}_{2}$ reduced emissions, CCGT power plants equipped with $\mathrm{CO}_{2}$ capture and sequestration unit will be a vital solution to be used. Carbon capture and utilization technologies are categorized into three sections, pre-combustion capture, post-combustion capture (PPC) and oxy-fuel combustion capture $[5,6]$. Among these technologies, post combustion capture eliminates the need for major to existing combustion processes and facilities; thus, it provides a way for near-term $\mathrm{CO}_{2}$ capture for existing stationary fossil fuel-based power plants and can be used for new ones in future with further advancement of the technology [7]. Different types underlie post-combustion carbon capture such as MEA-solvent based chemical absorption process [8], adsorption process [9], membrane technology [10] and temperature swing adsorption [11]. Post-combustion $\mathrm{CO}_{2}$ capture based on monoethanol-amine (MEA) is one of the most feasible approaches and recognized as the first choice for most demonstration projects due to its high technical maturity, large-scale applicability, good absorption effect and strong ability to remove $\mathrm{CO}_{2}$ from low $\mathrm{CO}_{2}$ concentration flue gas and very effective when integrating with CCGT power plant [12]. The current commercially available gas turbine technologies, CCGT with post combustion capture systems have been reported to have higher thermal efficiencies, and appear likely to give low total electricity costs and incurs lower capital costs, when compared with pre-combustion capture and oxy-fuel technology [13]. However, flue gases from natural gas-fired power plants raise challenges for post combustion capture technologies due to the relatively low $\mathrm{CO}_{2}$ concentration which decreases partial pressure of $\mathrm{CO}_{2}$ and then escalates the required reboiler duty which will finally impact net plant efficiency [14]. The main drawback that appears when integrating a post-combustion carbon capture unit with CCGT is the high reduction in power plant efficiency due to solvent regeneration requirement and auxiliaries load of the capture unit. Energy consumption due to integrating PCC can be decreased by adjusting the configuration of the system structure. For instance, the exhaust gas recirculation (EGR) process has demonstrated that $\mathrm{CO}_{2}$ concentration is increased in flue gas, the power penalty is relatively decreased and overall performance of the power plant is enhanced. Various studies were conducted on the amount of energy deducted from different types of power plants integrated with distinct PCC technologies were found to range from 20 to $60 \%$ of the overall output power [15].

Integration of PPC using $30 \mathrm{wt} \%$ MEA absorption technology with power plants has shown a notable reduction in net efficiency with $9.7 \%$. The highest contributor of the total thermal energy losses was for reboiler heat duty required to regenerate the solvent, compression of produced gaseous $\mathrm{CO}_{2}$ and the parasitic powers of PCC circulating pumps [16]. Global contributions focused on two main bases to partially reduce the issues concerned with lost energy after integrating PCC to power plants. The first pillar is increasing $\mathrm{CO}_{2}$ content in the feed of PCC unit by a replacing fraction of the excess air entering combustion box by either circulation part of the exhaust gas, steam injection or water vaporization to control the flame temperature and combustion gas produced after combustion chamber. Burning more fuel which used as a comburant to the excess air in exhaust gas. Exhaust gas recirculation (EGR) is recycling part of the exhaust gas back to the gas turbine inlet to be combusted with fuel and air. Process simulation models and experimental works have been initiated for the effect of absorption process using monoethanolamine (MEA) with strength (30 wt $\%$ ) solution with water on the reboiler specific duty and size of contactor column with improving the $\mathrm{CO}_{2}$ levels in the inlet gas, results from process models revealed that a notable reduction in specific reboiler duty happened when $\mathrm{CO}_{2}$ levels rise to 6 vol\%. Further, increase in the concentration of $\mathrm{CO}_{2}$, the specific reboiler duty still decreases but relatively slower [17]. Jordán et al. [18] have showed that, using $40 \%$ of EGR ratio on 400 MWe CCGT integrated with MEA based capture plant, will increase the $\mathrm{CO}_{2}$ levels in the inlet stream to PCC unit from $4.2 \mathrm{vol} \%$ to $7.05 \mathrm{vol} \%$ and also decrease the mass flow rate of the feed entering the unit. As a result of that, the required thermal energy witnessed a reduction from 3.6 to $3.52 \mathrm{GJ} / \mathrm{tCO}_{2}$ and noticeable decrease $16 \%$ in levelized cost of energy (LCOE). Simulation work is done by Junjiang et al. [19] on $391 \mathrm{MW}_{\mathrm{e}}$ CCGT equipped with solvent based post-combustion carbon capture plant. Integrating PCC with CCGT has reduced power plant efficiency by $7.8 \%$. They proposed three different configurations. First one involving EGR with power plant and carbon capture plant, the results showed that applying 35\% EGR decreased energy penalty percentage from 13.95 to $12.46 \%$ and increased efficiency around $2 \%$. The second one is recovering waste heat from the system using double-pressure organic Rankine cycle (ORC), the power generation efficiency increased efficiency approximately $1 \%$. The third configuration was using cold gas stream to generate power which increased efficiency by around $2.51 \%$. Agustín et al. [20] showed that EGR is a viable technique after increasing the efficiency of the CCGT power plant by $0.5 \%$ points which reduced the reboiler duty and capture plant size.

Renewable energy has a high potential in decreasing energy penalties than the other strategies that were discussed. Renewable energy includes wind, photovoltaic and solar thermal. The potential of using solar energy in industrial processes was reviewed and discussed in the work done by Sharma et al. [21] where solar energy is used in a wide range of industries such as food processing, textile, pulp, paper, chemical, pharmaceutical, cement, and leather products. The chemical industries which include distillation columns heated by a reboiler usually requires a 
temperature range between $\left(100-200^{\circ} \mathrm{C}\right)$ and the heat transfer fluid used is usually hot water or steam. A life cycle approach was studied by on $300 \mathrm{MW}_{\mathrm{e}}$ coal-fired power plant integrated with PCC plant and assisted by Wang et al. [22] using parabolic trough solar collectors they proposed two configurations, the first one is solar assisted plant which directly heating regenerator reboiler and the second one solar assisted repowering stage applying thermal energy for high pressure feedwater preheater. Results showed that, a high increase in LCOE in the case of reboiler direct heating compared to the second system and the output power loss reduced about $16.62 \mathrm{MW}$ while in the second configuration, no energy loss was detected. Wang et al. [23] constructed a solar assisted pilot module to test the performance of the system. Parabolic Trough Collector (PTC) and Linear Fresnel Reflector (LFR) were evaluated to provide heat duty for solvent regeneration. The results showed that, the two types can handle the required temperature. However, PTC expressed more efficiency than LFR. Lambert et al. [24] utilized solar energy by using solar power tower to support CCGT integrated with a pre-combustion carbon capture unit. They also applied EGR which took place after the compression stage of the gas turbine. EGR reduced the specific energy penalty from 15.3 to $13.6 \%$ and the renewable option was able to reduce energy loss associated with capture plant. Simulation model carried by Asiri et al. [25] on $555 \mathrm{MW}_{\mathrm{e}}$ CCGT plant integrated with post combustion carbon capture plant using amine located in Mexico. They adopted solar plant using parabolic trough solar collectors to assist post combustion carbon capture with reboiler heat load $258 \mathrm{MW}_{\text {th }}$ with and without thermal energy storage. Their results showed that the most optimum design was applying (SkeyFuel Sky) collector with $6 \mathrm{~h}$ of thermal energy storage had the best energy production for reboiler heat duty is $250 \mathrm{MW}_{\text {th }}$ due to thermal energy storage (TES) compared to system without TES which provided only $190 \mathrm{MW}_{\mathrm{th}}$.

According to the above literature review, the power loss after integrating carbon capture unit can be reduced by using exhaust gas recirculation due to carbon dioxide increase that is reflected on the reboiler thermal load which is the main cause of power plant penalty. Designing solar thermal plant to support $100 \%$ of the reboiler duty thermal load which in return will minimize the parasitic loads. Moreover, through deep analysis of what was done in the above-mentioned literature review. In this article, the researchers aimed to fill the gap that existed in the previous works. As none of the preceding works had implemented a fully integrated system with carbon capture plant, increasing carbon concentration by using EGR, using solar thermal plant to take $100 \%$ of reboiler thermal load and study the impact of EGR on the solar plant, designing $\mathrm{CO}_{2}$ onshore pipeline and calculating levelized cost of energy (LCOE) for the overall system based on EGR ratios.

\section{System description}

The proposed system is integrating CCGT power plant with post-combustion carbon capture plant equipped with EGR configuration and solar thermal plant using parabolic trough solar collectors to provide reboiler thermal load during the available sun hours instead of extracting low-pressure steam from the power plant. $\mathrm{CO}_{2}$ is transported via onshore pipeline to be used as a feedstock for petrochemical product. CCGT is composed of two gas turbines, steam turbines and PCC have two main sections, $\mathrm{CO}_{2}$ absorption unit by $\mathrm{MEA}$ and $\mathrm{CO}_{2}$ compression section. A schematic process flow diagram for CCGT integrated with PCC and compression is shown in Fig. 1.

\subsection{Combined cycle gas turbine power plant description}

The main components of the plant are an air compressor (AC), gas turbine (GT) and heat recovery steam generator (HRSG) with two stage pressure steam turbines high pressure steam turbine (HPST) and low-pressure steam turbine (LPST). The air is compressed by an axial air compressor and then mixed with natural gas in the combustion chamber before to combustion. The flue gases resulted from the combustion will go through the turbine impellers and then drive the turbine. The flue gases are discharged through HRSG to extract the remaining heat for water preheating and steam generation. HRSG consists of two steam generation systems called low pressure evaporator and high-pressure evaporator, it drives a steam turbine to generate electricity in form of a steam Rankine cycle. EGR configuration is the recycling of a specified portion of the flue gas from the outlet of HRSG to the air compressor for mixing with fresh air. EGR enhances $\mathrm{CO}_{2}$ concentration in the flue gas inlet to capture unit and reduces the penalty of the system with no big change in plant main structure as mentioned before in the literature. A schematic diagram of the CCGT power plant is shown in Fig. 2. 


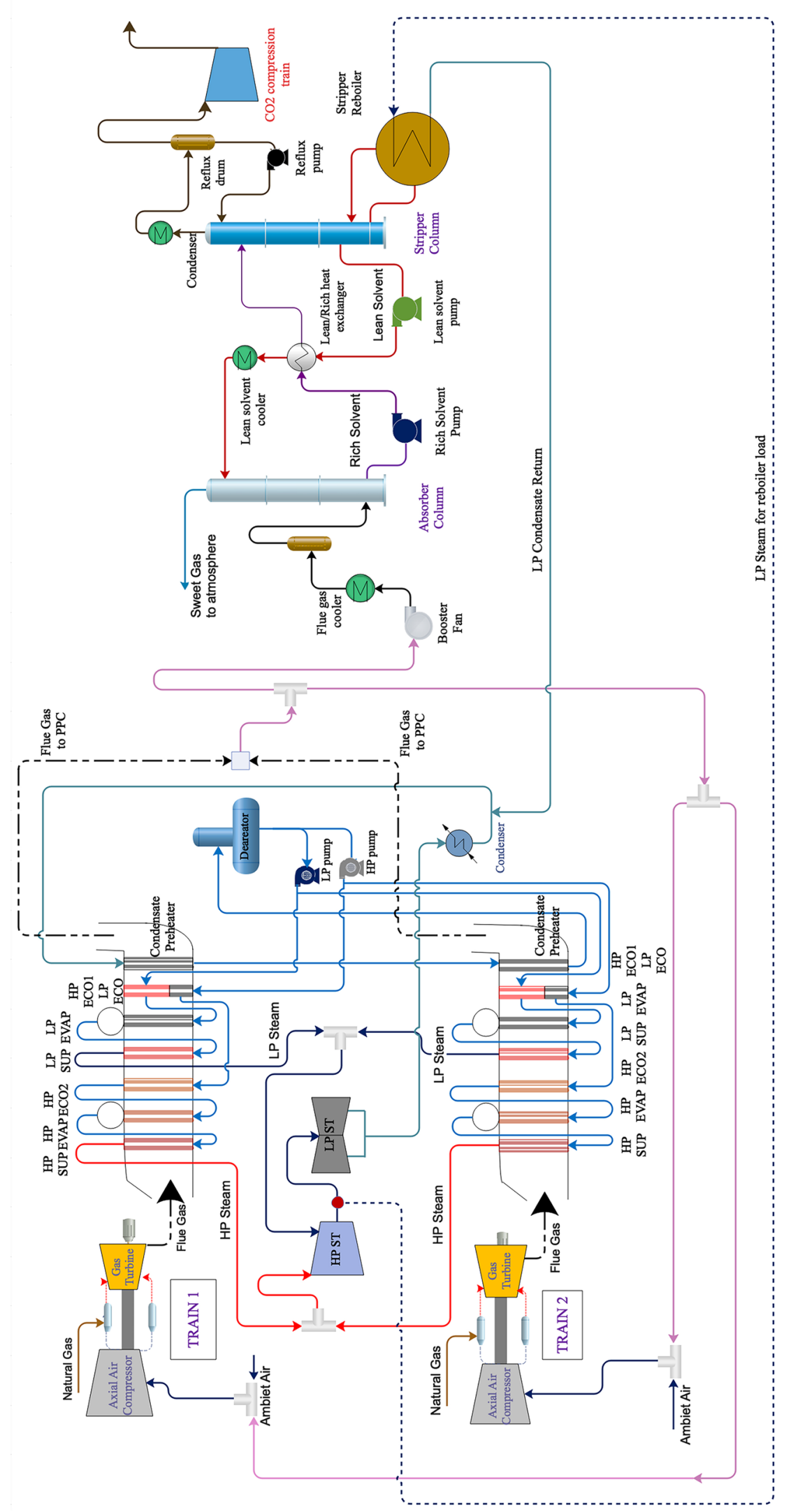

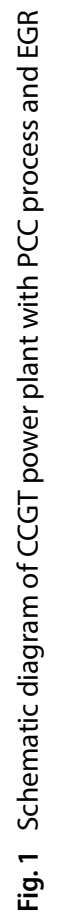




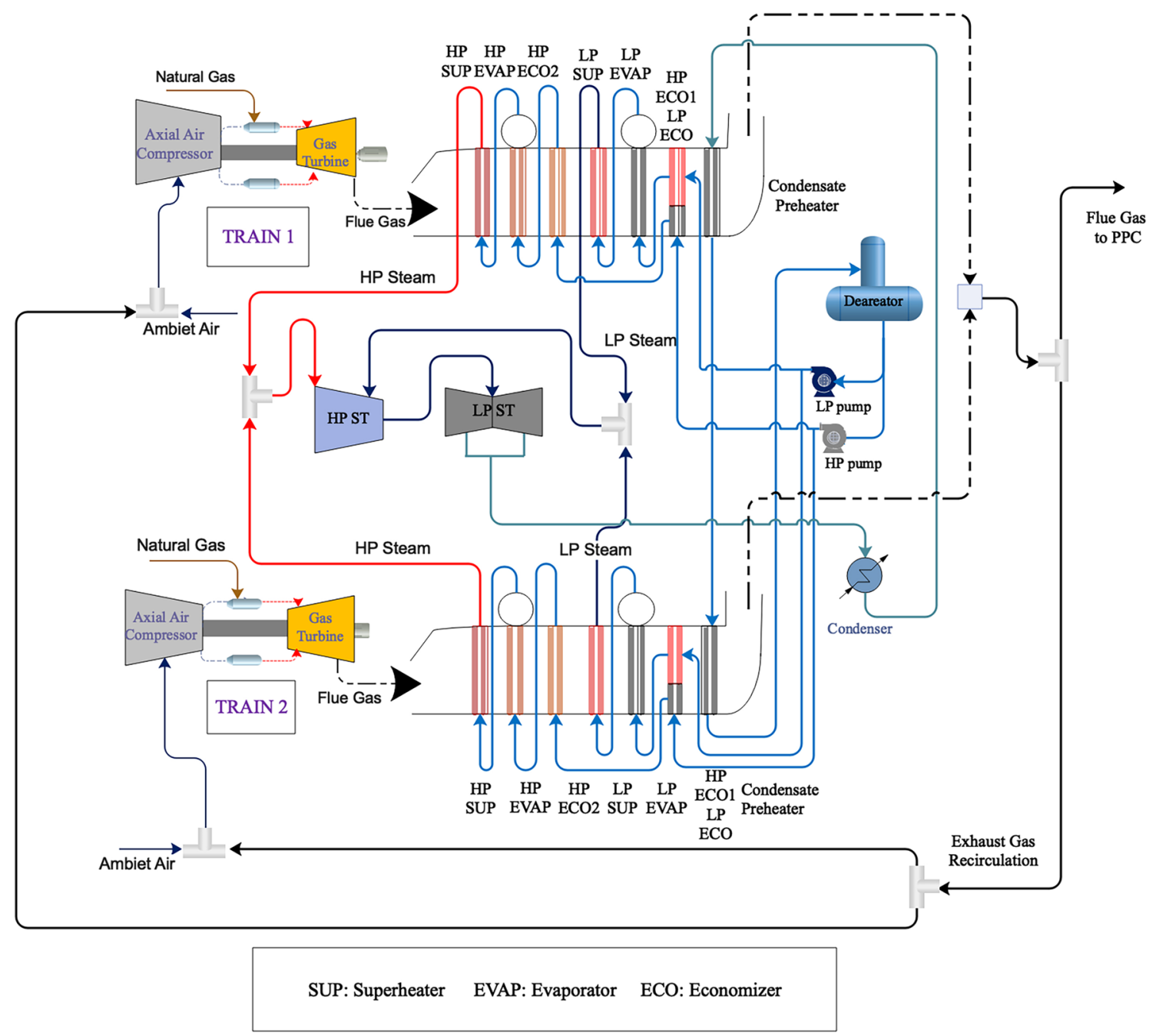

Fig. 2 Schematic diagram of CCGT power plant

\subsection{Post-combustion carbon capture plant description}

The PCC unit consists of $\mathrm{CO}_{2}$ capture and compression unit as shown in Fig. 3. The flue gas from the HRSG outlet is introduced to the contactor or absorber column where absorption reaction takes place. The capture unit uses MEA solvent with ( $30 \% \mathrm{wt}$ ) solution with water [18]. The $\mathrm{CO}_{2}$-free gas, called sweet gas, is discharged from the column overhead to the atmosphere. However, the liquid containing $\mathrm{CO}_{2}$ is called a rich solution that leaves the tower from the lower end and is preheated using the hot stream that left the regenerator tower to optimize the heat utilization of the unit and then flows to the stripper column. $\mathrm{CO}_{2}$ is separated from the regenerator overhead and solvent without $\mathrm{CO}_{2}$ is called lean solvent is cooled and directed again to absorber tower. The traces of $\mathrm{CO}_{2}$ and water mixture from stripper overhead are cooled and condensed and recycled back to the tower. The non-condensed phase which is mainly $\mathrm{CO}_{2}$ is compressed and pumped through the onshore pipeline.

\subsection{Solar industrial process heating}

Industrial process heating (IPH) involves heating tool that provides heat transfer medium for specific user which requires this heat for a final product. This heat can be transferred directly or indirectly, the direct method includes 




Fig. 3 Schematic diagram of PCC unit

heating the desired material instantly, while the indirect requires another stream which is called heat transfer medium is heated and then transfer the heat to the final destination. Implementing heat transfer medium in industrial process heating relays on the type of application which requires the heat. The heat transfer fluid must have some features which make it as a good option for most of the industries. These features such as: low vapor pressure, high heat capacity, low viscosity, low degradation rate and less corrosive. Most of the heat transfer mediums used in industries involves thermal oil, steam and pressurized water. Steam is the most dominant heat transfer fluid used in industrial process. From the above literature review, it can be seen that the solar thermal plant is used as a mitigation method to minimize the thermal load of the PCC plant. Solar energy utilized in the industrial process heating is one of the promising methods as an alternative option for energy supplier to a lot of oil importing countries. The steam is generated by heating water in a heat exchanger. Parabolic trough solar collectors are used to collect solar heat, heat is picked up by working fluid which is called heat transfer fluid (HTF) which extracts heat from the collectors, and then heats the water until it converted into steam. The steam is finally directed to the PCC reboiler to regenerate the solvent.

\subsubsection{Solar thermal plant with thermal energy storage}

The higher energy requirement makes it economically useful to increase dispatchability in the device by thermal storage combined with solar energy. The uses of thermal storage in the industry are demonstrated in Fig. 4. Thermal energy storage (TES) is the most common source of energy supply for potential use by concentrating solar thermal power plants. The primary driver of construction of a storage facility in solar power plants is also the transient quantity of solar radiation. The solar thermal storage system typically comprises three main elements, storage medium, heat transfer mechanism and containment system. The energy stored can take the form of sensible or latent heat or even chemicals. The aim of the part of the process of heat transfer is to supply and collect energy from the media. TES is used for containment to reduce system losses. Sensible heat storage involves materials such as molten salts and synthetic oils. In this configuration the thermal energy is retained by increasing the temperature of the fluid. The difference of heat and temperature during charging and discharging is used in this system. The quantity of heat depends on the specific heat of the medium and the storage content. Latent heat systems are built based on the principle of phase change in a material at a constant temperature. The storage process is nearly isothermal 
Fig. 4 Schematic diagram of SIPH supporting plant

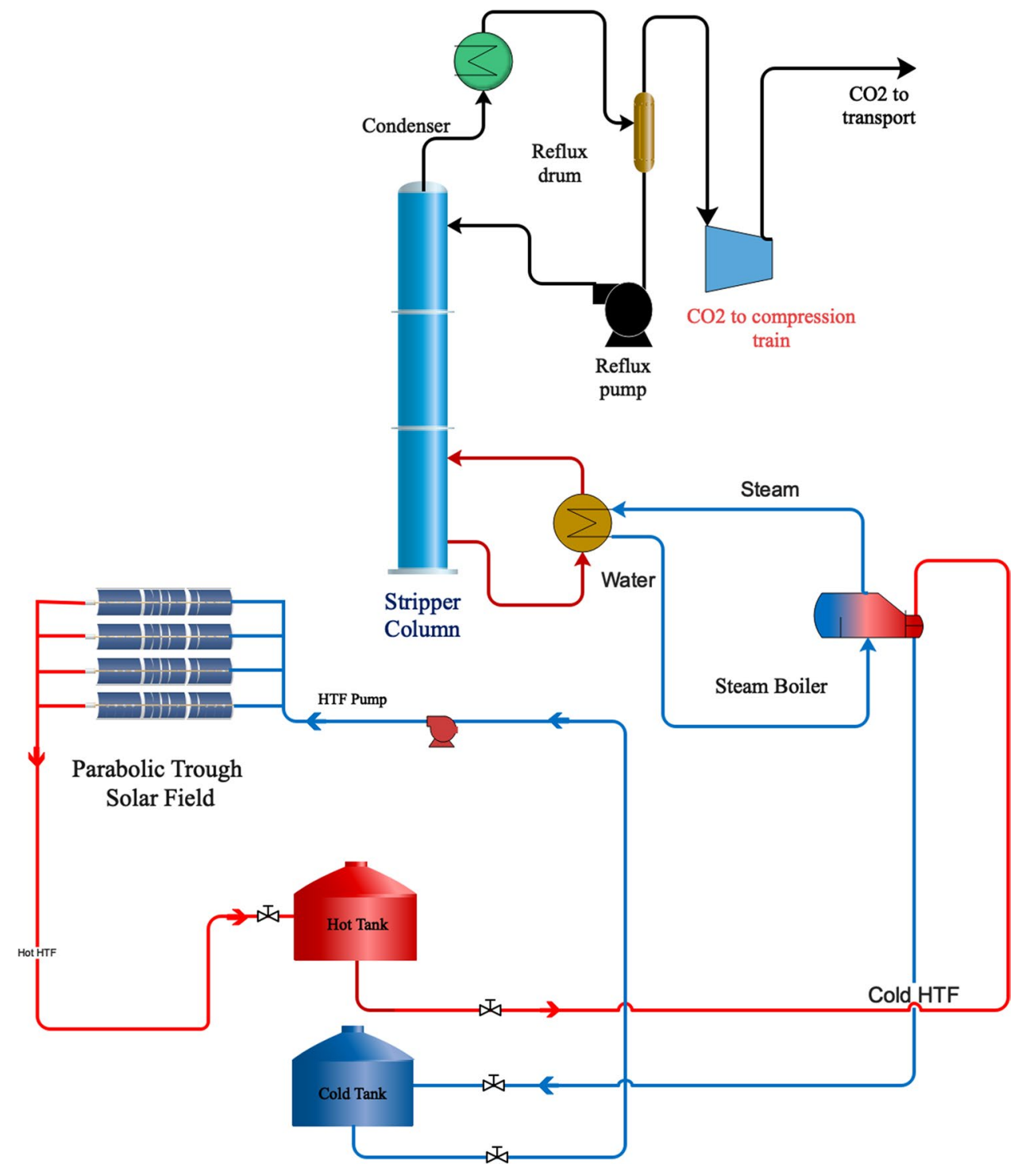

which provides a higher amount of energy compared to sensible heat storage system. This is very beneficial when combined with solar thermal plants to reduce system intermittences.

\subsubsection{System design description}

The full heat demand for the amine regeneration is provided by the solar field which will support $100 \%$ of the thermal load of carbon capture plant. Figure 4 illustrates the configuration of the solar thermal plant with TES that fulfils reboiler duty. The system actually composed of three main parts; the solar field to collect heat from the sun, a reboiler to extract the required heat load for carbon capture unit and a thermal storage system to save energy for later use. The two tanks (hot and cold) configuration to store energy was assumed in this study to improve the intermittency in the system. The hot tank holds a high temperature thermal fluid, while the cold tank holds the cold recycled fluid after the energy was extracted by the reboiler. The solar field charging process is based on direct or indirect methods. The difference between them is the medium used. Indirect method involves two tank system using a thermal storage media in addition to HTF. This will require additional heat exchanger to transfer heat between the two fluids. In this study direct energy storge was used. The CSP models concerned with IPH have some differences from the original models which involve electricity production. In concentrated solar plant with electricity production, the solar plant is coupled to the normal steam Rankine cycle thermal power block where both produces steam and generate electricity, but in case of the IPH model the power block section is ignored where the solar field energy is used to provide direct steam or heating for different 
thermal processes. In cloudy days the plant is backed up with TES system. In case of TES is not working or unable to be charged during winter, reboiler duty is supplied by the low-pressure steam cross-over point and it will affect the power plant output power accordingly.

\section{Research methodology}

\subsection{Model establishment}

To analyze the system with fewer complications, the following assumptions are considered in the simulation, in order to help the solver converging smoothly specially heat exchanger module.

1) CCGT is simulated in the steady state model.

2) No leakages are occurred in the different configurations of the system.

3) The energy loss and friction loss in all equipment are neglected.

4) The heat exchange between the environment and equipment is also neglected.

\subsubsection{Energy balance of the combined cycle gas turbine power plant}

For a CCGT power plant, the power output derives from a gas turbine and a steam turbine. The gas turbine and axial air compressor are connected on a single shaft by a mechanical device. The net power output of the gas turbine is shown as follows [26]:

$$
W_{G T}=\left[\frac{W_{g t}-W_{a c}}{\eta_{m e c h}}\right] \times\left[\eta_{g e n}\right]
$$

where $W_{g t}$ gas turbine power output $681.8 \mathrm{MW}, W_{a c}$ air compressor power consumption $280 \mathrm{MW}, \eta_{\text {mech }}$ mechanical efficiency $99.8 \%$ and $\eta_{\text {gen }}$ is the generator efficiency $99.8 \%$.

The net power output of the steam turbine can be expressed as follows [26]:

$$
W_{S T}=\left[W_{H P S T}+W_{L P S T}\right] x_{g e n}-\left[W_{H P P}+W_{L P P}\right]
$$

where $W_{\text {HPST, }} W_{\text {LPST }}$ mechanical work of high-pressure and low-pressure steam turbines $62.43 \mathrm{MW}$ and $81.6 \mathrm{MW}$ respectively, and $W_{H P P, W L P P}$ are the consumed power by high-pressure and low-pressure recirculation pumps $1.603 \mathrm{MW}$ and $0.04 \mathrm{MW}$.

The total power output of the CCGT power plant can be expressed as follows [26]:

$$
W_{\text {net }_{C C G T}}=W_{G T}+W_{S T}
$$

Table 1 Air and fuel composition inlet to gas turbine

\begin{tabular}{lll}
\hline Parameters & Air & Fuel \\
\hline Mass flow rate $(\mathrm{kg} / \mathrm{s})$ & 650 & 18.8 \\
Pressure $(\mathrm{bar})$ & 1 & 15 \\
$\mathrm{LHV}(\mathrm{KJ} / \mathrm{kg})$ & - & 48,453 \\
$\mathrm{~N}_{2}$ & $79.5 \%$ & - \\
$\mathrm{O}_{2}$ & $20.5 \%$ & - \\
$\mathrm{CO}_{2}$ & - & $0.01 \%$ \\
$\mathrm{CH}_{4}$ & - & $95.4 \%$ \\
$\mathrm{C}_{2} \mathrm{H}_{6}$ & - & $4.24 \%$ \\
$\mathrm{C}_{3} \mathrm{H}_{8}$ & - & $0.3 \%$ \\
$\mathrm{C}_{4} \mathrm{H}_{10}$ & - & $0.04 \%$ \\
$\mathrm{C}_{5} \mathrm{H}_{12}$ & - & $0.01 \%$ \\
\hline
\end{tabular}


Table 2 Model parameters of CCGT process

\begin{tabular}{lll}
\hline Description & Unit & Values \\
\hline Turbine inlet temperature & ${ }^{\circ} \mathrm{C}$ & 1050 \\
Compression ratio & - & 10.44 \\
Turbine exhaust temperature & ${ }^{\circ} \mathrm{C}$ & 515 \\
HP turbine inlet pressure & $\mathrm{bar}$ & 106 \\
LP turbine inlet pressure & $\mathrm{bar}$ & 5 \\
Superheated steam temperature & ${ }^{\circ} \mathrm{C}$ & 500 \\
Ambient temperature & ${ }^{\circ} \mathrm{C}$ & 25 \\
Generator Efficiency & $\%$ & 90 \\
\hline
\end{tabular}

Table 3 Comparison between CCGT actual data and simulation

\begin{tabular}{llll}
\hline Parameter & Unit & Actual Data & Simulation \\
\hline GT power & MW & 290 & 351 \\
ST power & MW & 190 & 144 \\
Plant net power & MW & 480 & 495 \\
Plant efficiency & $\%$ & 56.02 & 56.6 \\
\hline
\end{tabular}

Table 4 Comparison of PCC simulation with referenced work

Table 5 PCC unit design parameters

\begin{tabular}{lll}
\hline Parameter & Benchmark work [26] & Simulation \\
\hline Absorber column trays & 14 & 13 \\
Stripper column trays & 10 & 8 \\
Reboiler Duty $\left(\mathrm{MW}_{\mathrm{th}}\right)$ & 161 & 165 \\
Reflux ratio & 0.1 & 0.3 \\
\hline
\end{tabular}

\begin{tabular}{lll}
\hline Preliminary design & Unit & Values \\
\hline Lean solvent flow rate & $\mathrm{kmole} / \mathrm{h}$ & 160,000 \\
Inlet gas flow rate & $\mathrm{kmole} / \mathrm{h}$ & 109,141 \\
No of absorber columns & - & 1 \\
No. stripper columns & - & 1 \\
Absorber capture efficiency & $\%$ & 85 \\
Flue gas inlet temperature & ${ }^{\circ} \mathrm{C}$ & 40 \\
Absorber pressure & bar & 1 \\
Stripper pressure & bar & 2 \\
\hline
\end{tabular}

\subsubsection{Efficiency of the power plant}

The calorific value $Q_{N G}$ of the combusted fluid entering the combustion chamber of the power plant is calculated as follows [19]:

$$
Q_{N G}=\dot{m}_{N G} X L H V
$$


where $L H V$ is the low heating value of natural gas $48,453 \mathrm{~kJ} / \mathrm{kg}, m_{N G}$ is mass flow rate of the fuel $18.08 \mathrm{~kg} / \mathrm{s}$.

Auxiliary equipment power consumption $\mathrm{W}_{\mathrm{aux}}$ consists of power consumption of cooling water and amine pumps is as follows [26]:

$$
W_{\text {aux }}=W_{\text {Amine }_{P_{\text {unps }}}}+W_{C O 2_{\text {Comp }}}+W_{C O 2_{P_{\text {Punp }}}}
$$

where $W_{\text {Amine_Pumps }} W_{\text {CO2_Comp }} W_{\text {CO2_pump }}$ are total power consumed by amine pumps, $\mathrm{CO}_{2}$ compressors and $\mathrm{CO}_{2}$ pump $0.15 \mathrm{MW}, 15.8 \mathrm{MW}$ and $0.5 \mathrm{MW}$ respectively.

The total power output of CCGT power plant is as follows [26]:

$$
W_{\text {total }}=W_{N e t_{C C G T}}-W_{\text {aux }}
$$

The efficiency of CCGT power plant is as follows [26]:

$$
{ }_{C C G T}=\frac{W_{\text {Total }}}{Q_{N G}}
$$

\subsubsection{Verification of power plant model}

The simulation of the CCGT power plant with PCC unit is simulated by Aspen Hysys V8.6 workflow. Gas turbine SIEMENS (V94.2) modelling used Peng-Robinson (PR) fluid package, while steam turbines were represented by ASME steam tables model. Gas turbine and steam turbines are simulated and compared with the actual output power and overall efficiency that represent Damietta power plant. The design data including feed air, fuel gas composition and other parameters are listed in Tables 1 and 2. The comparison between actual data and simulation results are listed in Table 3. There is a small deviation between actual and simulation data. Therefore, the accuracy of the model is verified.

\subsubsection{Verification of carbon capture process}

The acid gas absorption using aqueous amines is performed by using the Amine package which uses Ken-Eisenberg or Li-Mather as thermodynamic models for the amine solutions. A model was selected as a benchmark that was reported as a master thesis work. This published work data and results were utilized in this project to validate Aspen Hysys model results and system performance [27]. Table 4 shows the comparison between the current work and the cited ones, along with the operating parameters of the system that are given in Table 5.

\subsection{Compression train and pipeline transportation}

$\mathrm{CO}_{2}$ compression train is modelled by Aspen Hysys, its load is accounted for the total parasitic loads. The operating pressure for the $\mathrm{CO}_{2}$ pipeline must be maintained at supercritical conditions or liquid dense phase with pressure above 73.8 bar [28]. A final compression stage discharge pressure of 73.8 bar and a pump is provided to raise the pressure to 110 bar, the compression and pumping are specified according to the work conducted by Herraiz [14]. The compression train consists of three centrifugal compressors, intercoolers and scrubbers. The pumping section was modelled in the same flowsheet with the compression train. $\mathrm{CO}_{2}$ transportation is the transition between capture and storage or usage, it's considered the lowest cost stage among the whole system. On land, $\mathrm{CO}_{2}$ can be transported by tankers, trucks, railcars and pipelines. The efficient way to transport $\mathrm{CO}_{2}$ is via the appropriate design of pipeline [28]. In this study, $\mathrm{CO}_{2}$ pipeline design calculations were done an excel spreadsheet. Pipeline material was also selected to best suit the specifications of the product.

\subsubsection{Mathematical model of $\mathrm{CO}_{2}$ pipeline}

An excel spreadsheet is used for pipeline design using the following equations.

The optimum inner diameter of the pipeline is estimated as follows [28]: 
Fig. 5 The effect of EGR ratio on $\mathrm{O}_{2}, \mathrm{CO}_{2}$ concentrations and Reboiler duty

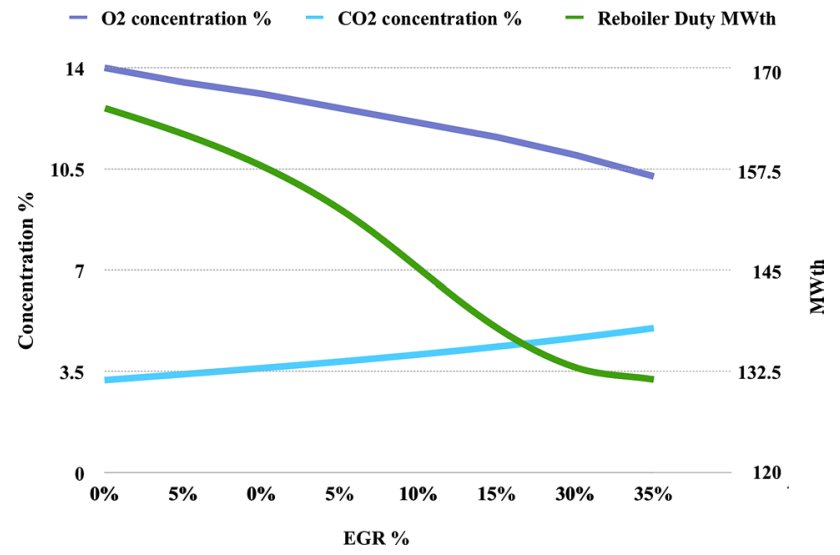

Table 6 Process parameters comparison

\begin{tabular}{lllll}
\hline Case & Unit & CCGT & CCGT+PCC & CCGT+PCC+EGR \\
\hline Gas turbine power & $\mathrm{MW}$ & 350 & 350 & 349 \\
HP steam turbine power & $\mathrm{MW}$ & 62.43 & 62.41 & 64.90 \\
LP steam turbine power & $\mathrm{MW}$ & 81.6 & 35.86 & 46.98 \\
Acid gas booster power & $\mathrm{MW}$ & $\mathrm{N} / \mathrm{A}$ & 3 & 1.79 \\
Power plant net output & $\mathrm{MW}$ & 495 & 430.65 & 444.11 \\
Total power penalty & $\mathrm{MW}$ & $\mathrm{N} / \mathrm{A}$ & 65.27 & 51.80 \\
Plant net efficiency & $\%$ & 56.61 & 49.15 & 50.62 \\
Exhaust mass flow rate & $\mathrm{kg} / \mathrm{s}$ & 976.1 & 976.1 & 628 \\
Exhaust gas CO ${ }_{2}$ content & $\mathrm{mole} \%$ & 3.2 & 3.2 & 5 \\
Exhaust gas outlet temperature & ${ }^{\circ} \mathrm{C}$ & 515.21 & 515.21 & 521.53 \\
Steam temperature & ${ }^{\circ} \mathrm{C}$ & 505 & 505 & 518 \\
Total absorber circulation rate & $\mathrm{kg} / \mathrm{s}$ & $\mathrm{N} / \mathrm{A}$ & 998.5 & 769.5 \\
Heat required in reboiler & $\mathrm{MWth}$ & $\mathrm{N} / \mathrm{A}$ & 165 & 131.5 \\
Net specific emissions & $\mathrm{kg}$ co2 $/ \mathrm{MWh}$ & 351.53 & 58.62 & 56.18 \\
\hline
\end{tabular}

$$
D_{\text {opt }}=0.363 \times Q_{v}^{0.45} \times \rho^{0.13} \times \mu^{0.025}
$$

where $Q v$ is $\mathrm{CO}_{2}$ flow rate $0.463 \mathrm{~m}^{3} / \mathrm{s}, \rho$ is density $98.88 \mathrm{~kg} / \mathrm{m}^{3}, \mu$ is viscosity $0.02285 \mathrm{cp}$, these values were obtained from Aspen simulation flowsheet.

The friction factor is estimated using the follow equation:

$$
\mathrm{f}=\frac{1.325}{\left[\ln \left(\left(\frac{\varepsilon}{3.7 D}\right)+\left(\frac{5.74}{R e^{0.9}}\right)\right)\right]^{2}}
$$

where $D$ is inner diameter $375 \mathrm{~mm}, \varepsilon$ is pipe roughness $0.259 \mathrm{~mm}$ for carbon steel.

The pressure drop per unit length is represented as follows [28]:

$$
\Delta \mathrm{P} / \mathrm{L}=\frac{8 f Q^{2}}{\rho \pi^{2} D^{5}}
$$

where $f$ is friction factor $0.0128, L$ is pipeline length $15 \mathrm{~km}$.

The thickness of pipeline is estimated as follows [29]: 


$$
t=\frac{P_{\max } D}{2\left(S F E-P_{\max }\right)}
$$

where, $P_{\text {max }}$ is the maximum operating pressure $10 \mathrm{MPa}, F$ is the design factor $0.72, S$ is the specific yield stress of pipe material $4137 \mathrm{MPa}, E$ is a longitudinal joint factor 1.

The pipeline weight is calculated using the following [30]:

$$
W_{s}=\pi L \rho_{\text {steel }} t\left(D_{i}+t\right)
$$

where, $t$ is wall thickness $9.46 \mathrm{~mm}, \rho_{\text {steel }} 7850 \mathrm{~kg} / \mathrm{m}^{3}$.

\section{Process integration}

\subsection{Combined cycle gas turbine power plant with carbon capture and exhaust gas recirculation}

The integration of the carbon sequestration plant will decrease the output power and efficiency of the CCGT power plant. The typical capture rate of post combustion carbon plant ranging from 85 to $90 \%$ of the $\mathrm{CO}_{2}$. In order to simulate on the least reboiler steam consumption rate, the removal rate $85 \%$ is selected for this project $[27,28]$. Integrating post combustion carbon capture unit, part of LP steam existing HPST to LPST is used for solvent regeneration in the reboiler resulting in decreasing the output power from LPST by $44 \%$. This reduced the power plant efficiency with nearly $13 \%$. To restore part of that lost power, EGR is implemented to increase carbon levels in the feed to carbon capture unit, this will support the partial pressure of the carbon in the stripper section and then decrease the required power to separate the carbon from the solvent. EGR is simulated at different ratios depending on the oxygen

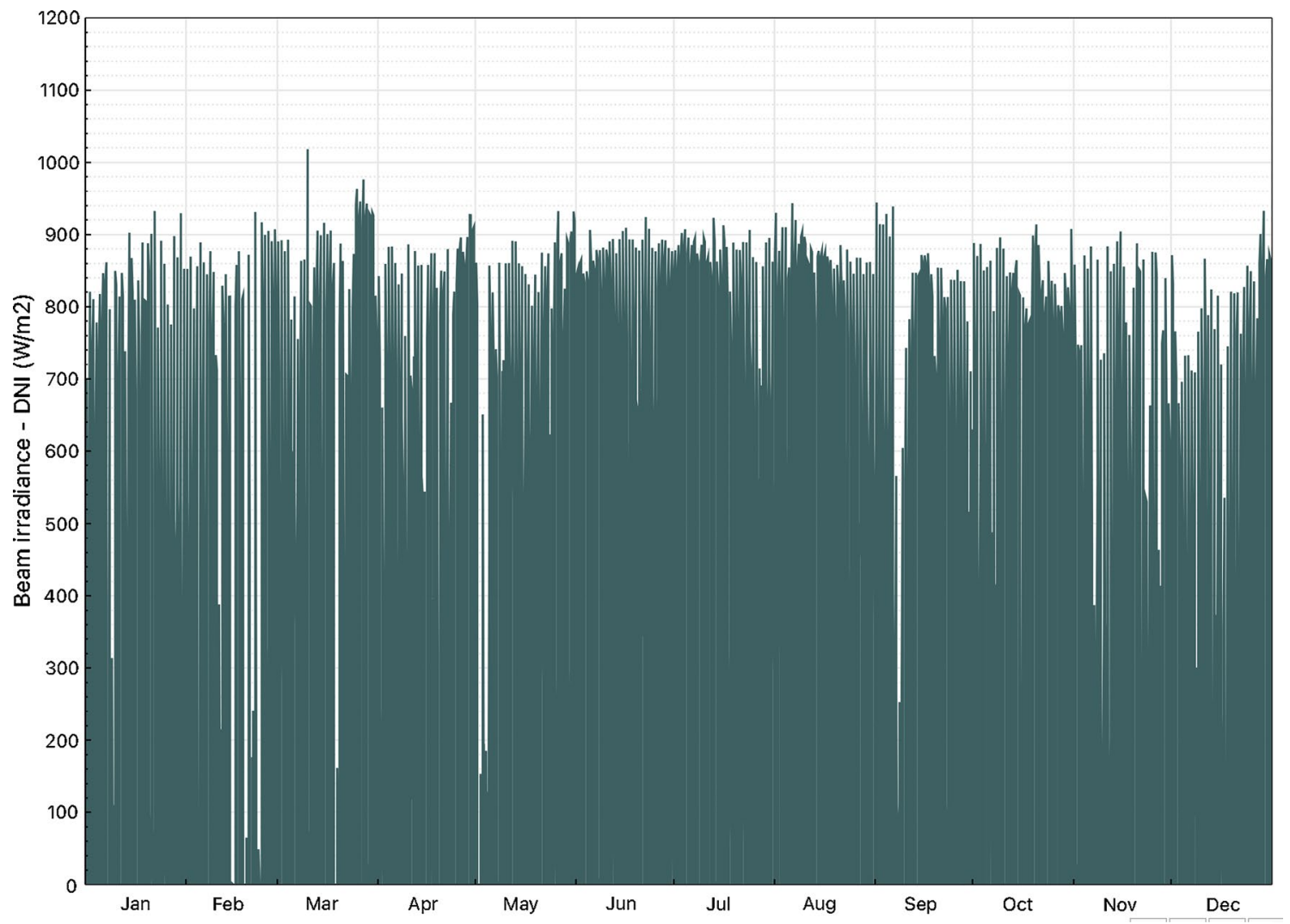

Fig. 6 Hourly DNI for parabolic trough collector at Damietta City 
levels returning back to the combustor. In order to determine the EGR ratio, the change of $\mathrm{O}_{2}$ concentration, $\mathrm{CO}_{2}$ concentration and capture energy consumption of the reboiler unit $\mathrm{CO}_{2}$ with $\mathrm{EGR}$ ratio are investigated as shown in Fig. 5. With increasing EGR ratio, the reboiler energy is gradually decreasing, $\mathrm{O}_{2}$ concentration decreases while $\mathrm{CO}_{2}$ increases. Previous studies have showed that, oxygen levels in the combustion chamber below $16 \%$, the flame shape and flue gas temperature will be affected negatively and can lead to oxygen starvation [14, 31, 32]. At 35\% EGR ratio, oxygen content was around $17 \%$, below that concentration, unburned hydrocarbon started to appear in the exhaust gas. Therefore, the EGR ratio of 35\% is selected in this paper. The system integrations results are shown in Table 6.

\subsection{Solar thermal plant integration}

\subsubsection{Site description and solar energy available}

The CCGT power plant is located in Kafr Al Battikh, a region in Damietta Governate, one of the coastal cities in Egypt. The plant is simulated for a period of one-year $(0 \mathrm{~h}$ to $8760 \mathrm{~h}$ ). For the simulation of the hypothetical CSP power plant, the site with direct normal irradiance (DNI) and the typical metrological year (TMY) data in the NREL database has been used to evaluate the performance of the parabolic trough solar thermal plant. The climate data includes hourly DNI, ambient temperature, wind speed, atmospheric pressure, sun angle and solar azimuth angle.

This region relies on medium solar radiation which enjoys Direct Normal Solar Irradiation (DNI) which equals according to solar atlas data approximately by $5.455 \mathrm{KWh} / \mathrm{m}^{2}$ per day. The Global Horizontal Irradiation (GHI) for Damietta is $5.425 \mathrm{KWh} / \mathrm{m}^{2}$ per day, the Diffuse Horizontal Irradiation (DHI) is $2.024 \mathrm{KWh} / \mathrm{m}^{2}$ per day and the recorded Direct Normal Irradiation (DNI) is $5.425 \mathrm{KWh} / \mathrm{m}^{2}$ per day $\left(\sim 1980 \mathrm{KWh} / \mathrm{m}^{2}\right.$ per year) [33].

Figure 6 shows the variation of normal irradiance per each month at Damietta. The maximum DNI of $7.7 \mathrm{KWh} / \mathrm{m}^{2}$ per day was recorded during June and July while the minimum $3.6 \mathrm{KWh} / \mathrm{m}^{2}$ per day of DNI during December. The average wind speed in Damietta is $4.33 \mathrm{~m} / \mathrm{s}$ lower than the critical wind speed of $15.64 \mathrm{~m} / \mathrm{s}$ that may lead to solar system structure collapse. The average amount of sun hours for this location is $14 \mathrm{~h}$ per day in June which is the longest time for sunshine in the year compared to $10 \mathrm{~h}$ in December which is the shortest time [34].

\subsubsection{Parabolic trough concentrated solar plant with thermal energy storage in solar industrial process heating}

Parabolic trough collector (PTC) is the best technology to reach high temperature ranges up to $550^{\circ} \mathrm{C}$ with optimum commercial concerns when compared to other solar technologies such as Fresnel collectors, solar towers and dish sterling [35]. PTC has a minimum energy loss by convection and conduction due to the annulus between the absorber tube and surrounding glass, and the absorber is coated with a material that has a solar radiation absorptivity higher than 0.95 and low emitted heat which lead to a good reduction of the radiation losses. The best used collector for SIPH applications is the (SkyFuel SkyTrough) solar collector assembly (SCA). This module had been used in Stillwater hybrid solar-geothermal plant in the USA [36]. A large number of studies that were simulated by system advisor model (SAM) have selected (Schott 2008 PTR80) as the optimum heat collector element (HCE) as it has the optimum efficiency which is enhanced by increasing the length of the receiver by four meters and above. Most of the studies that used SAM to simulate parabolic trough solar plants recommended only two types among all the fluids. Therminol VP-1 and HITEC Solar Salt are the suitable candidates because they have a good heat capacity, higher specific heat and higher density and lower viscosity which gives them the ability to flow through the pipe with good heat transfer properties [37]. In this work, direct thermal energy storage which involves using the same HTF will be evaluated [25].

\subsubsection{Mathematical model of solar field with thermal energy storage}

For the heat gained by the collector is as follows [25]:

$$
Q_{C o l}=D N I X A_{C} X \eta_{C}
$$

where, $\eta_{C}$ collector efficiency $0.68 \%$ [29], DNI $875 \mathrm{~W} / \mathrm{m}^{2}$.

The collector outlet temperature of heat transfer fluid (HTF) is as follows [25]: 


$$
T_{o c}=T_{i}+\frac{Q_{C o l}}{\dot{m} x C_{p}}
$$

where, $\dot{m}$ single loop mass flow rate $12 \mathrm{~kg} / \mathrm{s}, \mathrm{T}_{\mathrm{i}}$ inlet temperature $130{ }^{\circ} \mathrm{C}, \mathrm{C}_{p} \mathrm{HTF}$ heat capacity $2.45\left(\mathrm{Kj} / \mathrm{kg}{ }^{\circ} \mathrm{C}\right)$.

The number of collectors is estimated as follows [25]:

$$
N_{c}=\frac{Q_{r}}{Q_{c o l}}
$$

where, $Q_{r}$ required thermal load for carbon capture plant (185 $\mathrm{MW}_{\mathrm{th}}$ to $151 \mathrm{MW}_{\mathrm{th}}$ ).

The Number of collectors per loop is calculated as follows:

$$
N_{C / L}=\frac{T_{o}-T_{i}}{T_{o c}-T_{i}}
$$

where, $T_{o}$ loop outlet temperature.

The total number of loops is expressed as follows [25]:

$$
N_{L}=\frac{N_{c}}{N_{C / L}}
$$

In case of implementing solar thermal storage system, extra calculations are involved in the model to calculate the additional heat to be used in later time.

The total HTF mass flow rate after adding thermal energy storage is as follows [25]:

$$
\dot{m}_{T}=N_{L} x \dot{m}
$$

The mass of HTF stored in the tanks is represented by the following [25]:

$$
m_{s}=\dot{m}_{T} x t_{s}
$$

where, $t_{s}$ is the storage time which is assumed to be $6 h$ [25]

The mass flow rate during the sun hours is estimated by the following:

$$
\dot{m}_{d}=\frac{m_{s}}{t_{d}}
$$

where, $t_{d}$ is the total sun hours $10 \mathrm{~h}$ for Damietta city.

The total number of collectors after adding thermal storage system is calculated as follows:

$$
N_{s}=\frac{\dot{m}_{d} x C_{p} x\left(T_{o}-T_{i}\right)}{t_{d}}
$$

The number of loops added after thermal energy storage is calculated as follows [25]:

Table 7 Solar thermal plant parameters without thermal storage

\begin{tabular}{llllll}
\hline EGR ratio (\%) & $\begin{array}{l}\text { Target load } \\
\left(\mathrm{MW}_{\mathrm{th}}\right)\end{array}$ & No. of loops & $\begin{array}{l}\text { Total no. of } \\
\text { collectors }\end{array}$ & $\begin{array}{l}\text { Annual Gross } \\
\text { Energy }\left(\mathrm{MWh}_{\mathrm{th}}\right)\end{array}$ & LCOE $\left(\$ / \mathrm{MWh}_{\mathrm{th}}\right)$ \\
\hline 0 & 185 & 94 & 470 & 401,855 & 21.54 \\
5 & 182 & 92 & 460 & 393,579 & 21.49 \\
10 & 178 & 90 & 450 & 385,024 & 21.41 \\
15 & 172 & 85 & 425 & 366,324 & 21.38 \\
20 & 165 & 81 & 405 & 349,389 & 21.31 \\
25 & 157 & 77 & 385 & 332,185 & 21.29 \\
30 & 152 & 62 & 372 & 321,490 & 21.21 \\
35 & 151 & 62 & 372 & 321,289 & 21.20 \\
\hline
\end{tabular}


- Incident thermal power (MWth)
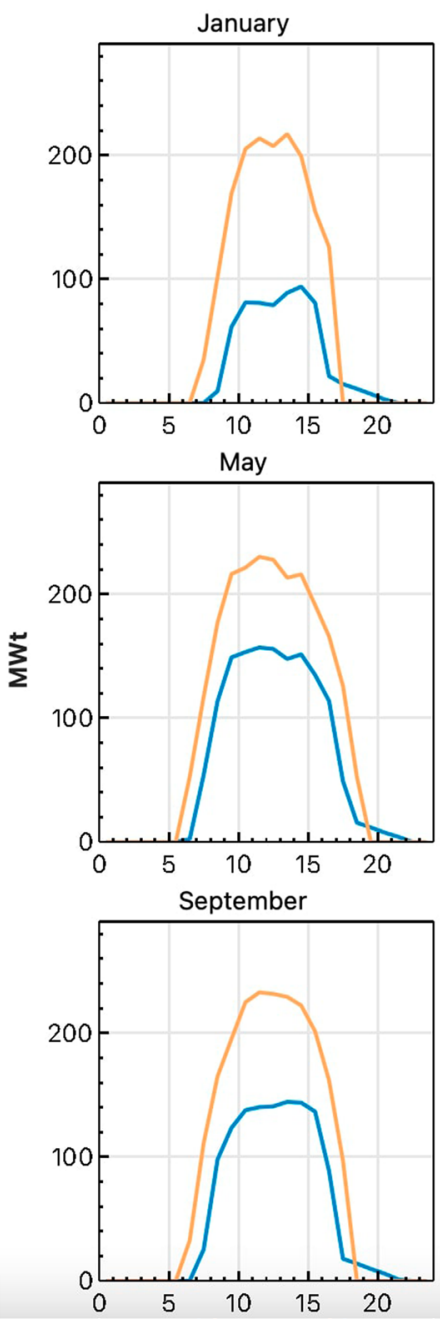
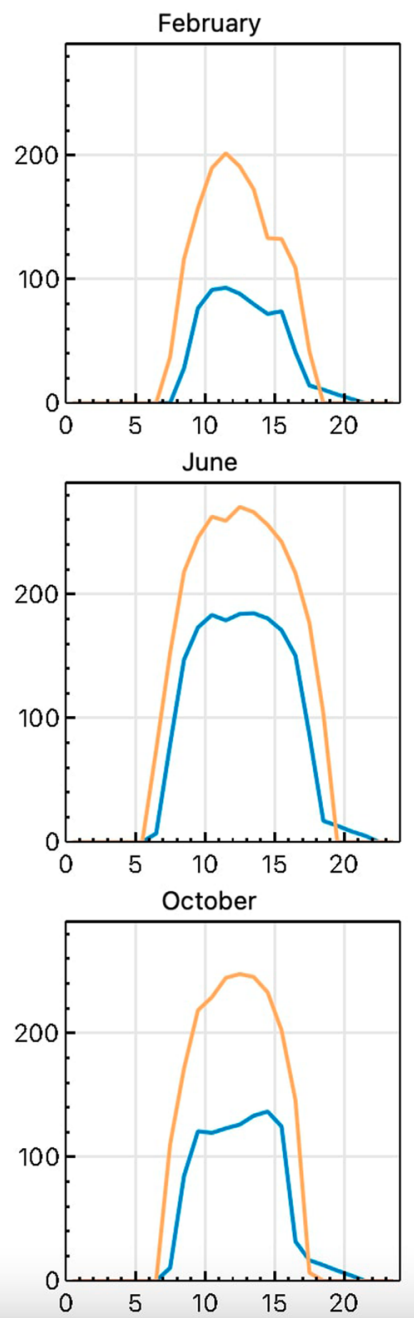

- Heat sink thermal power (MWth)
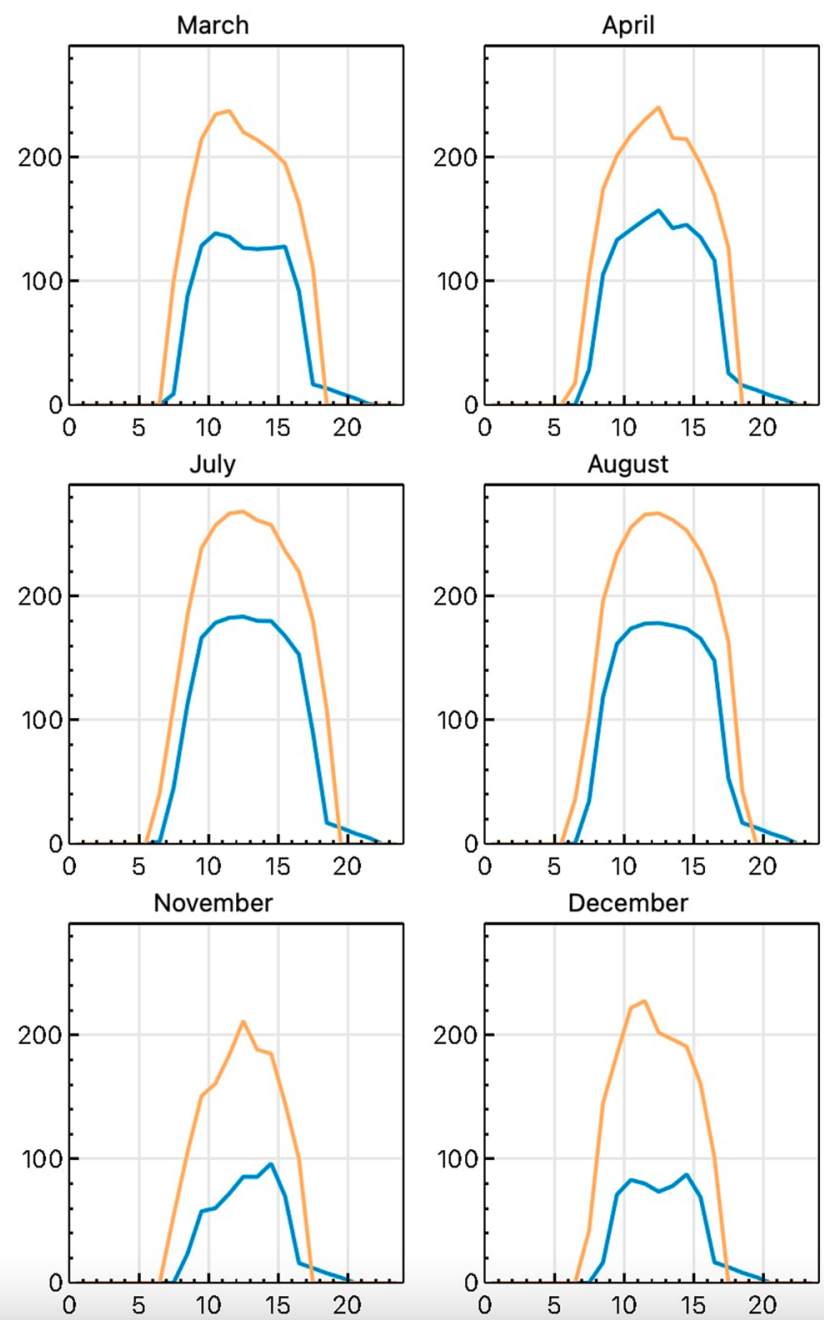

Fig. 7 Hourly thermal power per month for solar plant without TES

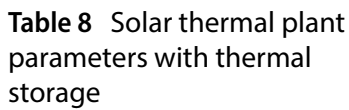
storage

\begin{tabular}{llllll}
\hline EGR ratio (\%) & $\begin{array}{l}\text { Target load } \\
\left(\mathrm{MW}_{\text {th }}\right)\end{array}$ & $\begin{array}{l}\text { Target receiver ther- } \\
\text { mal power (MWth) }\end{array}$ & No. of loops & $\begin{array}{l}\text { Annual net } \\
\text { energy }\left(\mathrm{MWh}_{\mathrm{th}}\right)\end{array}$ & LCOE $\$ / \mathrm{MWh}_{\text {th }}$ \\
\hline 0 & 185 & 277.5 & 140 & 597,873 & 21.20 \\
5 & 182 & 273 & 138 & 589,521 & 21.15 \\
10 & 178 & 267 & 135 & 576,586 & 21.00 \\
15 & 172 & 258 & 127 & 545,865 & 20.81 \\
20 & 165 & 247 & 121 & 520,227 & 20.53 \\
25 & 157 & 235 & 116 & 498,573 & 20.14 \\
30 & 152 & 228 & 93 & 479,959 & 20.05 \\
35 & 151 & 226.5 & 93 & 479,958 & 20.03 \\
\hline
\end{tabular}

$$
N_{L s}=\frac{N_{s}}{N_{C / L}}
$$

The total number of loops of solar field and thermal storage is represented as follows [25]: 
- Incident thermal power (MWth)

- Field thermal power leaving (MWth)

- Heat sink thermal power (MWth)
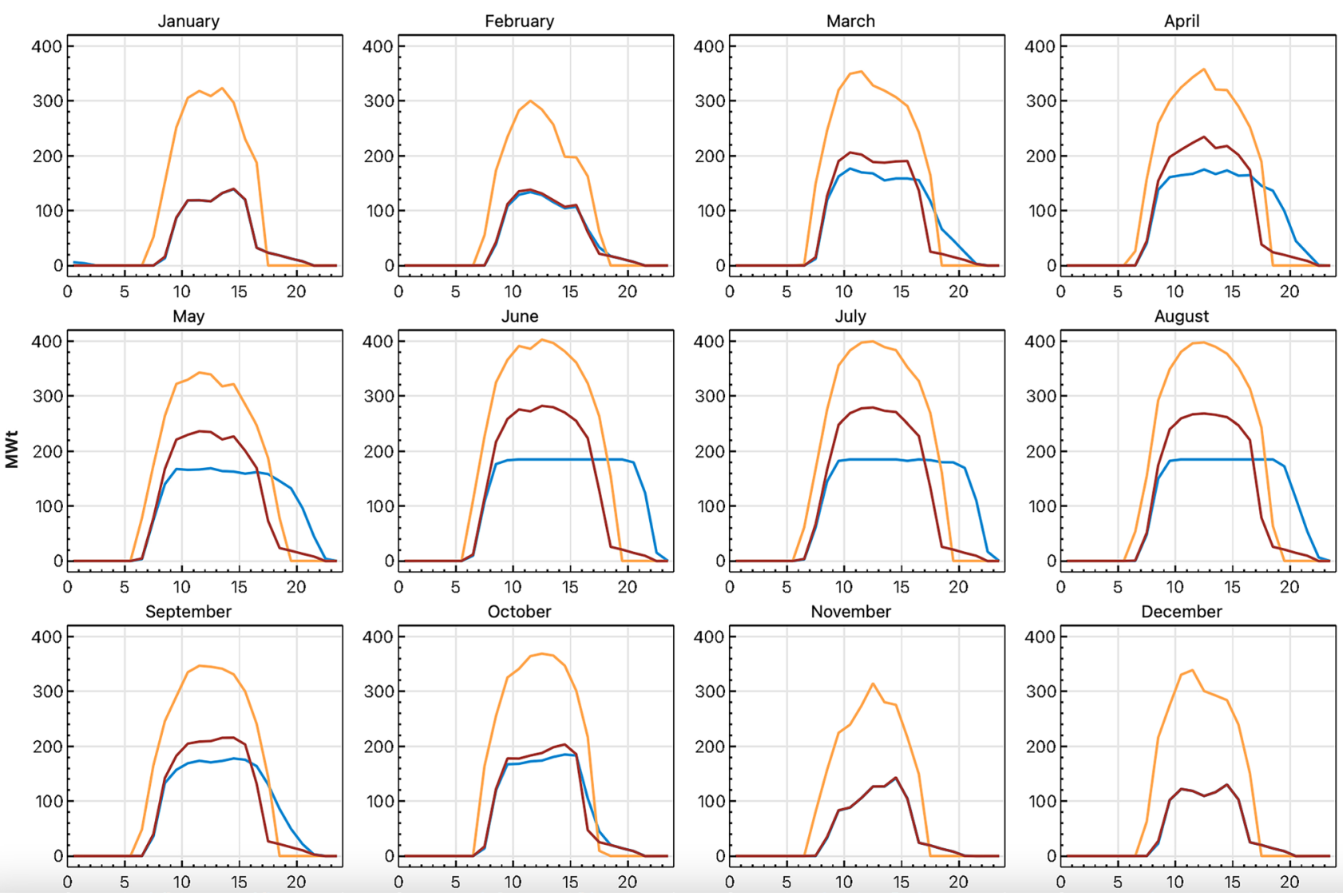

Fig. 8 Hourly thermal power per month for solar plant with TES

$$
N_{T L}=N_{L s}+N_{L}
$$

\section{Results and discussion}

\subsection{Solar thermal plant without thermal energy storage}

The constant heat loss is $4 \%$ (default value in SAM), HTF temperature rise is $100^{\circ} \mathrm{C}$ in the solar system, the temperature of HTF leaving solar collectors and the regeneration reboiler are $230^{\circ} \mathrm{C}$ and $130^{\circ} \mathrm{C}$ respectively. Therminol VP- 1 synthetic oil is a suitable candidate to be used as HTF because it has a good heat capacity, higher specific heat and higher density and lower viscosity which gives them the ability to flow through the pipe with good heat transfer properties with mass flow rate per loop $6 \mathrm{~kg} / \mathrm{s}$ and the DNI is $875 \mathrm{~W} / \mathrm{m}^{2}$. The solar collector and thermal receiver that were selected are SkeyFuel Sky and Schott PTR 80 respectively. These conditions are constant for the two design cases. Table 7 shows the solar thermal configurations according to different PCC heat loads required. The SM calculated was 1.02 which gives the same required thermal load. Based on the simulator results for the $185 \mathrm{MW}$ plant with annual thermal energy of 401,855 MW for reboiler duty and auxiliary power, the plant is capable of producing thermal power from 6 A.M to 7 P.M on average ( $12 \mathrm{~h}$ per day) depending on the time of the year. The highest energy produced is during the months of June, July and August. On the other hand, the lowest energy produced is in December approximately $80 \mathrm{MW}_{\mathrm{th}}$. The hourly energy production in each month is represented in Fig. 7; it also shows the variation of incident thermal energy affects the energy production. The maximum heat generated for reboiler is recorded as $180 \mathrm{MW}_{\mathrm{th}}$ and maximum incident power recorded during July with $270 \mathrm{MW}_{\text {th }}$. 


\subsection{Solar thermal plant with thermal energy storage}

In this configuration, the same collectors and receiver types are used as in the previous design. The available land area for installing the thermal was measured using the Google Maps tool, which is nearly $1.3 \mathrm{~km}^{2}$. The suitable SM estimated by SAM according to the available land area next to the power plant is 1.5. TES was introduced to decrease the intermittency in the system when the sunlight is not available. The target energy receiver thermal power is higher than the actual required thermal heat to able to store this surplus energy for the later use. The density of Therminol VP-1 oil is $934.245 \mathrm{~kg} /$ $\mathrm{m}^{3}$. The system specifications after simulating thermal energy storage are represented in Table 8.

From the results, the power generation increased considerably from March to September as illustrated in Fig. 8. The highest solar thermal produced from the system is $280 \mathrm{MW}_{\text {th }}$ while the heat sink power recorded at $180 \mathrm{MWth}$. The amount of thermal energy storage charging and discharging thermal power during the day fluctuates according to the availability of solar radiation. From the previous results, solar thermal plant with TES showed more efficient performance than the normal system as it managed to provide more solar production with slightly lower cost. Applying EGR had decreased the LCOE of system by $\left(\$ 0.34 / \mathrm{MWh}_{\text {th }}\right)$ in case of solar thermal system with no TES, while it was decreased by $\left(\$ 1.17 / \mathrm{MWh}_{\mathrm{th}}\right)$ in case of TES system.

\section{Plant cost model}

One of the key objectives of this work is to determine the effect of implementing both PCC, PTC plants with compression and transportation on the levelised cost of electricity (LCOE) from the 495 MW CCGT. In most academic studies the cost calculation is done by two methods, net present value (NPV) or LCOE over the economic lifetime. The calculation of LCOE includes data of rated capacity MW, capital cost \$, operating and maintenance costs \$, efficiency $\%$, fuel LHV and capacity factor \%. Equipment costs are estimated most of the time from other studies and reveal a wide variety of uncertainties. Equations below are used to calculate LCOE on 25 years of the total plant life. The cost model was calculated using an excel spreadsheet at each EGR ratio. Based on the calculations, the capital cost of the whole integrated system kept decreasing after implementing EGR, the lowest cost was at $35 \%$ ratio. Thus, the results at $35 \%$ only are presented in this paper.

Three cases are considered; one where the CCGT alone, CCGT + PCC + Compression and CCGT + PCC + Compression + Solar thermal plant.

The LCOE for the all whole system is calculated as follows [31]:

$$
\operatorname{LCOE}\left(\frac{\$}{M W h}\right)=\frac{C A P \times C R F}{C F \times \text { Netpower }}+(\text { O\&MCosts })
$$

Fig. 9 Cost of avoidance for CCGT+PCC and CCGT + PCC + Solar system

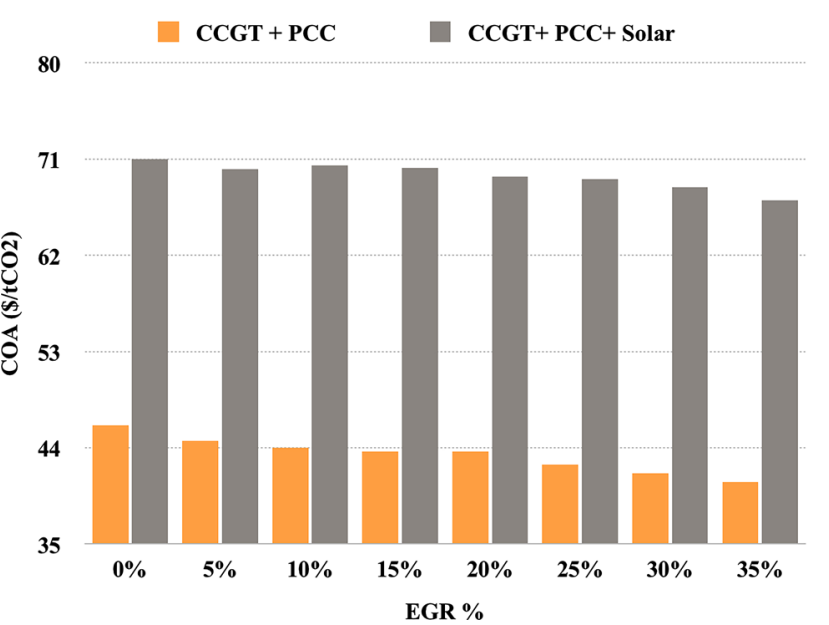


Table 9 Solar thermal plant different studies simulated by SAM

\begin{tabular}{lllcc}
\hline & Unit & Asiri et al. [25] & Bravo et al. [44] & $\begin{array}{l}\text { Current } \\
\text { study (35\% } \\
\text { EGR) }\end{array}$ \\
\hline Thermal Load & MW & 258 & 219.47 & 151 \\
Solar Multiple & - & 1.54 & 1.3 & 1.5 \\
Solar collector duty & MW $_{\text {th }}$ & 397.32 & 372.1 & 226.5 \\
LCOE of solar system (thermal) & $\$$ MWh $_{\text {th }}$ & 31.4 & $40.57^{\text {a }}$ & 20.03 \\
\hline
\end{tabular}

where, CAP is total system capital cost, CRF is capital recovery factor, CF capacity factor $80 \%$ [32].Capital cost of CCGT (based on the official data from the plant), PCC, compression station and onshore pipeline are $80 \mathrm{M} \$, 136 \mathrm{M}$ [38], $2 \mathrm{M \$}$, $1 \mathrm{M} \$$ respectively.

O\&M in $\$ / M W h$ costs based on Egyptian natural gas price $3.01 \$ / G J$ [39] for CCGT which includes only natural gas 19.08 \$/MWh and water costs 0.009 \$MWh [40]. In PCC plant, natural gas increased 26.37 \$MWh to provide the additional loads required by the capture plant, water demand increased as well $0.01246 \$ / M W h$ and MEA solvent makeup is added to the cost $8.68 \$ / \mathrm{MWh}$ [41]. The operating costs for compression and onshore pipeline are assumed to be $4 \%$ of the capital cost [30].

The capital recovery factor is estimated as follows:

$$
C R F=\frac{i(1+i)^{n}}{(1+i)^{n}-1}
$$

where, $i$ is interest rate $11.3 \%$ [42], $n$ is plant life in years.

The cost of solar collectors is calculated as follows [23]:

$$
C_{\text {solar }}=\frac{N_{C} \times C \times F_{\text {solarfield }}}{1 \times 10^{6}}
$$

where, $C$ is unit cost per collector $3000 \$, \mathrm{Fs}_{\text {olar field }}$ is cost factor for solar field 1.5 [25]. The capital cost of the overall solar field $75 \$ \mathrm{M}$ this cost breakdown is solar collectors with TES tanks plus engineering cost and Egyptian customs which are $20 \%$ and $7.5 \%$ [43] of the total capital cost respectively. O\&M cost is assumed to be $1.5 \%$ of the capital cost.

The cost of $\mathrm{CO}_{2}$ avoidance is estimated as follows [32]:

$$
C O A=\frac{[L C O E]_{\text {withCCS }}-[L C O E]_{\text {withoutCCS }}}{\left[\mathrm{CO}_{2}\right]_{\text {emittedwithoutCCS }}-\left[\mathrm{CO}_{2}\right]_{\text {emittedwithCCS }}}
$$

Using the previous equations, the LCOE for CCGT as reference plant was estimated to be (34.31 \$/MWh). Integrating carbon capture plant, $\mathrm{CO}_{2}$ compression and transportation with CCGT made LCOE increased dramatically. However, involving EGR at the mentioned ratios had a small reduction in LCOE from (47.98 \$/MWh to $46.71 \$ / \mathrm{MWh}$ ). Implementing solar thermal plant with energy storage that operates for $12 \mathrm{~h}$ to support carbon capture plant parasitic loads will

Table 10 CCGT power plant surveyed with key metrics shown

\begin{tabular}{llllll}
\hline & Unit & $\begin{array}{l}\text { Luo and } \\
\text { Wang [45] }\end{array}$ & $\begin{array}{l}\text { Vaccarelli } \\
\text { et al. [46] }\end{array}$ & $\begin{array}{l}\text { Adams and Mac } \\
\text { Dowell [32] }\end{array}$ & Current study \\
\hline CCGT load & MW & 453 & 383 & 420 & 495 \\
Capture rate & $\%$ & 90 & 90 & 90 & 85 \\
NG price & \$/GJ & 8.05 & 6 & 5.27 & 3.01 \\
MEA price & \$/tonne & 1777 & 2630 & 2164 & 2880 \\
LCOE of CCGT plant & \$/MWh & 71.1 & 55 & 51 & 34.30 \\
$\begin{array}{l}\text { LCOE of CCGT with PCC } \\
\begin{array}{l}\text { LCOE after integrating } \\
\text { solar thermal pant }\end{array}\end{array}$ & \$/MWh & 119.6 & 75 & 69 & 46.71 \\
\hline
\end{tabular}


provide the thermal heat instead of the extra fuel injected to produce this thermal load. This saved fuel flow is considered to be revenue for the plant, as this solar boiler has no $\mathrm{CO}_{2}$ emissions and, in return, would save carbon taxes $\left(\$ / \mathrm{tCO}_{2}\right)$. However, solar thermal plant increased LCOE by $20.71 \%$ (from $\$ 46.71 / \mathrm{MWh}$ to $\$ 57.61 / \mathrm{MWh}$ ). EGR slightly reduced LCOE from $(\$ 57.61 / \mathrm{MWh}$ to $\$ 56.81 / \mathrm{MWh})$. The cost of avoidance $(C O A)$ is calculated for the reference plant integrated with carbon capture unit it showed $\left(\$ 46.07 / \mathrm{t} \mathrm{CO}_{2}\right)$ but it decreased after the applying EGR to be $(\$ 40.80 / \mathrm{tCO})$. The cost also escalated after integration of solar plant to reach $\left(\$ 74.56 / \mathrm{tCO}_{2}\right)$. EGR had a remarkable decreased in COA from $(\$ 74.56 /$ $\mathrm{tCO}_{2}$ to $\$ 70.04 / \mathrm{MWh}$ ) as shown in Fig. 9.

\title{
6.1 Comparison between LCOE of different studies simulated parabolic trough solar thermal plant by SAM Software
}

There are some academic papers which used SAM to simulate parabolic trough solar plant that used to compensate reboiler heat duty after integrating carbon capture plant. This comparison is used to show the variation of LCOE of only PTC solar thermal plant as shown in Table 9.

\subsection{Differences between various studies of combined cycle gas turbine power plant integrated with carbon capture unit}

A survey was undertaken to demonstrate the difference in LCOE between the previous studies and the current work. These studies are related to combined cycle gas turbine with nearly similar load. It is not easy to judge how practical the financial results are due to the differences of natural gas prices, capturing rate, local electricity prices and post combustion carbon capture prices. However, technical and economic data were extracted from different studies and listed in Table 10. This survey was undertaken just to expand the total reach of the same goal for carbon capture from exhaust from the combined cycle power plant.

\section{Conclusion}

In the current study, a simulation model of CCGT was built using Aspen Hysys software. The natural gas combined power plant with two gas turbines and two pressure levels steam turbines (HP \& LP) has a total power capacity of $495 \mathrm{MW}$. $\mathrm{CO}_{2}$ increased (from $3.2 \%$ mole to $5.1 \%$ mole) at $35 \%$ ratio EGR. The carbon capture plant was simulated by the same software, PCC power input which is considered as a parasitic load were reduced by increasing EGR ratio by $20 \%$ (from 65.27 MW to $51.80 \mathrm{MW}$ ). The solar thermal plant is simulated to fully provide $100 \%$ of capture plant thermal load and auxiliaries during daytime. SAM software was utilized at different EGR ratios. For $185 \mathrm{MW}_{\mathrm{th}}$, solar plant maximum and minimum thermal power were $180 \mathrm{MW}_{\text {th }}$ and $90 \mathrm{MW}_{\text {th }}$ respectively. Adding TES system improved the thermal power needed for the reboiler in the months that had low productivity in the other model while the months which had the maximum production kept constant for a longer period of time along the day. LCOE was decreased when applying the thermal storage system and further reduction in cost was seen after applying EGR. The cost is calculated at the different EGR ratios, it showed a reduction ( $\$ 47.92 / \mathrm{MWh}$ to $\$ 46.71 / \mathrm{MWh}$ ) of LCOE when integrating PCC with the power plant at the $35 \%$ ratio. Implementing the solar thermal plant has added an extra expense ( $\$ 47.92 / \mathrm{MWh}$ to $\$ 57.61 / \mathrm{MWh})$. Applying EGR had reduced the cost ( $\$ 57.61 / \mathrm{MWh}$ to $56.81 / \mathrm{MWh})$ at $35 \%$ ratio. The cost of $\mathrm{CO}_{2}$ avoidance was also estimated and also decreased remarkably at $35 \%$ ratio $\left(\$ 74.56 / \mathrm{tCO}_{2}\right.$ to $\left.\$ 70.04 / \mathrm{tCO}_{2}\right)$. Based on current findings, relative to normal combustion conditions, $35 \%$ of EGR was found to be the optimal and less expensive choice.

\footnotetext{
Acknowledgements I would like to express my special thanks of gratitude to my primary supervisor, Ayman Abbas who guided me throughout the project and provided me with most of the technical data. I would also like to thank my friends and family who supported me deep insight into the study.
}

\begin{abstract}
Authors' contributions All authors contributed to the study conception and design. Material preparation, data collection and analysis were performed by AAA and AA. The first draft of the manuscript was written by [AAA] and all authors commented on previous versions of the manuscript. All authors read and approved the final manuscript.
\end{abstract}

Funding Not applicable. 
Data availability The datasets generated during and/or analysed during the current study are available from the corresponding author on reasonable request.

Code availability Not applicable.

Ethics approval and consent to participate Not applicable.

Competing interests The authors declare that there are no conflicts of interest related to this study.

Open Access This article is licensed under a Creative Commons Attribution 4.0 International License, which permits use, sharing, adaptation, distribution and reproduction in any medium or format, as long as you give appropriate credit to the original author(s) and the source, provide a link to the Creative Commons licence, and indicate if changes were made. The images or other third party material in this article are included in the article's Creative Commons licence, unless indicated otherwise in a credit line to the material. If material is not included in the article's Creative Commons licence and your intended use is not permitted by statutory regulation or exceeds the permitted use, you will need to obtain permission directly from the copyright holder. To view a copy of this licence, visit http://creativecommons.org/licenses/by/4.0/.

\section{References}

1. Luo X, Wang M, Chen J. Heat integration of natural gas combined cycle power plant integrated with post-combustion CO2 capture and compression. Fuel. 2015;151:110-7.

2. Freeman J, Hellgardt K, Markides CN. An assessment of solar-powered organic Rankine cycle systems for combined heating and power in UK domestic applications. Appl Energy. 2015;138:605-20.

3. Esquivel-Patiño G, Serna-González M, Nápoles-Rivera F. Thermal integration of natural gas combined cycle power plants with CO 2 capture systems and organic Rankine cycles. Energy Conver Manag. 2017;151:334-42. https://doi.org/10.1016/j.enconman.2017.09.003.

4. Hu Y, Xu G, Xu C, Yang Y. Thermodynamic analysis and techno-economic evaluation of an integrated natural gas combined cycle (NGCC) power plant with post- combustion CO2 capture. Appl Therm Eng. 2017;111:308-16.

5. Osman Al, Hefny M, Abdel Maksoud MIA, et al. Recent advances in carbon capture storage and utilisation technologies: a review. Environ Chem Lett. 2020. https://doi.org/10.1007/s10311-020-01133-3.

6. Salvi BL, Jindal S. Recent developments and challenges ahead in carbon capture and sequestration technologies. SN Appl Sci. $2019 ; 1: 885$.

7. Rasel M, Masud KM, Mohammad R, Malcolm L. Post combustion carbon capture and storage in existing coal power plant: importance and recent development. 2011.

8. Zhai R, Liu H, Wu H, Yu H, Yang Y. Analysis of Integration of MEA-Based CO2 capture and solar energy system for coal-based power plants based on thermo-economic structuraltheory. Energies. 2018;11:1284.

9. Jiang L, Gonzalez-Diaz A, Ling-Chin J, Roskilly AP, Smallbone AJ. Post-combustion CO2 capture from a natural gas combined cycle power plant using activated carbon adsorption. Appl Energy. 2019;245:1-15.

10. Kárászová M, Zach B, Petrusová Z, Červenka V, Bobák M, Šyc M, Izák P. Post-combustion carbon capture by membrane separation. Rev Separ Purif Technol. 2020;238:116448. https://doi.org/10.1016/j.seppur.2019.116448.

11. Lillia D, Bonalumi C, Grande GM. A comprehensive modeling of the hybrid temperature electric swing adsorption process for $\mathrm{CO} 2$ capture. Int J Greenhouse Gas Control. 2018;74:155-73.

12. Mohamed K, René G, Philippe J, Jose V, Jean-Marc A, Chakib B. Pre-combustion, post-combustion and oxy-combustion in thermal power plant for CO2 capture. Appl Thermal Eng. 2010;30:53-62.

13. IEA. Energy Technology Perspectives 2017, IEA, Paris; 2017. https://www.iea.org/reports/energy-technology-perspectives-2017

14. Herraiz L, Fernández ES, Palfi E, Lucquiaud M. Selective exhaust gas recirculation in combined cycle gas turbine power plants with postcombustion $\mathrm{CO}_{2}$ capture. Int J Greenh Gas Control. 2018;71:303-21.

15. Mokhtar M, Ali M, Khalilpour R, Abbas A, Shah N, Hajaj A, et al. Solar-assisted post-combustion carbon capture feasibility study. Appl Energy. 2012;92:668-76.

16. Feron P. Absorption-based post-combustion capture of carbon dioxide. UK impring of Elsevier: Duxford; 2016. p. 779-92.

17. Aboudheir A, EIMoudir W. Performance of formulated solvent in handling of enriched $\mathrm{CO} 2$ flue gas stream. Energy Procedia. 2009;1(1):195-204.

18. Pérez Sánchez J, Aguillón Martínez J, Mazur Czerwiec Z, Zavala Guzmán A. Theoretical assessment of integration of CCS in the Mexican electrical sector. Energy. 2019;167:828-40.

19. Bao J, Zhang L, Song C, Zhang N, Guo M, Zhang X. Reduction of efficiency penalty for a natural gas combined cycle power plant with post-combustion CO2 capture: Integration of liquid natural gas cold energy. Energy Conver Manag. 2019;198:111852.

20. Alcaráz-Calderon A, González-Díaz M, Mendez Á, González-Santaló J, González-Díaz A. Natural gas combined cycle with exhaust gas recirculation and $\mathrm{CO}_{2}$ capture at part-load operation. J Energy Inst. 2019;92(2):370-81.

21. Sharma A, Sharma C, Mullick S, Kandpal T. Solar industrial process heating: a review. Renew Sustain Energy Rev. 2017;78:124-37.

22. Wang J, Zhao J, Wang Y, Deng S, Sun T, Li K. Application potential of solar-assisted post-combustion carbon capture and storage (CCS) in China: A life cycle approach. J Cleaner Prod. 2017;154:541-52.

23. Wang F, Zhao J, Li H, Deng S, Yan J. Preliminary experimental study of post-combustion carbon capture integrated with solar thermal collectors. Appl Energy. 2017;185:1471-80.

24. Lambert T, Hoadley A, Hooper B. Process integration of solar thermal energy with natural gas combined cycle carbon capture. Energy. 2014;74:248-53. 
25. Asiri J, Asiri JM, Oztekin A, Romero CE. Design a Solar Thermal System for a Carbon Capture Pilot-Scale Plant. 2020.

26. Liu Z, Karimi I. Simulation of a combined cycle gas turbine power plant in Aspen HYSYS. Energy Procedia. 2019. https://doi.org/10.1016/j. egypro.2019.01.901.

27. Birkelund ES. $\mathrm{CO}_{2}$ absorption and desorption simulation with Aspen HYSYS. Tromsø: University of Tromsø; 2013. p. 33-6.

28. Peletiri S, Rahmanian N, Mujtaba I. CO2 Pipeline Design: A Review. Energies. 2018;11(9):2184. https://doi.org/10.3390/en11092184.

29. Chandel M, Pratson L, Williams E. Potential economies of scale in $\mathrm{CO} 2$ transport through use of a trunk pipeline. Energy Conversion Management. 2010;51(12):2825-34.

30. Kang K, Seo Y, Chang D, Kang S, Huh C. Estimation of CO2 Transport Costs in South Korea Using a Techno-Economic Model. Energies. 2015;8(3):2176-96. https://doi.org/10.3390/en8032176.

31. Pan M, Aziz F, Li B, Perry S, Zhang N, Bulatov I, Smith R. Application of optimal design methodologies in retrofitting natural gas combined cycle power plants with CO2 capture. Appl Energy. 2016;161:695-706. https://doi.org/10.1016/j.apenergy.2015.03.035.

32. Adams T, Mac Dowell N. Off-design point modelling of a 420 MW CCGT power plant integrated with an amine-based post-combustion CO2 capture and compression process. Appl Energy. 2016;178:681-702.

33. Solargis, Damietta city. https://globalsolaratlas.info/map?c=31.417823\%2C31.792717\%2C11

34. Average Weather in Damietta, Egypt, Year-Round - Weather Spark. https://weatherspark.com/y/96952/Average-Weather-in-DamiettaEgypt-Year-Round

35. Liaqat K, Anss M, Ali A, Mengal A. Modeling and simulation of a $100 \mathrm{MW}$ concentrated solar thermal power plant using parabolic trough collectors in Pakistan. IOP Conf Series. 2018;414:012032. https://doi.org/10.1088/1757-899x/414/1/012032.

36. Kurup P, Zhu G, Turchi C. Solar Process Heat Potential in California, USA. Proc Eurosun. 2016. https://doi.org/10.18086/eurosun.2016.02.07.

37. Bishoyi D, Sudhakar K. Modeling and performance simulation of 100 MW PTC based solar thermal power plant in Udaipur India. Case Stud Thermal Eng. 2017;10:216-26. https://doi.org/10.1016/j.csite.2017.05.005.

38. Intergovernmental panel on climate change (IPCC). Special report on carbon dioxide capture and storage. Cambridge: Cambridge University Press; 2005. p. 431.

39. Mondal M, Ringler C, Al-Riffai P, Eldidi H, Breisinger C, Wiebelt M. Long-term optimization of Egypt's power sector: Policy implications. Energy. 2019;166:1063-73. https://doi.org/10.1016/j.energy.2018.10.158.

40. Egyptian Holding company for water and waste water.

41. Jones D. Technoeconomic Evaluation of MEA versus Mixed Amines and a Catalyst System for CO2 Removal at Near-Commercial Scale at Duke Energy Gibson 3 Pulverized Coal Plant and Duke Energy Buck Natural Gas Combined Cycle (NGCC). Plant. 2019. https://doi. org/10.2172/1499969.

42. Central Bank of Egypt.

43. Abou-Ghattas NAA, El-Ghetany A, H. H. . Modelling of an Energy Saving Solar Water Heating system for industrial low temperature applications. IRJET. 2019;12:4774-84.

44. Bravo J, Charles J, Neti S, Caram H, Oztekin A, Romero C. Integration of solar thermal energy to improve NGCC with CO2 capture plant performance. Int J Greenhouse Gas Control. 2020;100:103111. https://doi.org/10.1016/j.ijggc.2020.103111.

45. Luo X, Wang M. Optimal Operation of MEA-Based Post-Combustion Carbon Capture Process for Natural Gas Combined Cycle Power Plants. Exergy Better Environ Improved Sustain. 2018;1:1377-91. https://doi.org/10.1007/978-3-319-62572-0_88.

46. Vaccarelli M, Carapellucci R, Giordano L. Energy and economic analysis of the CO2 capture from flue gas of combined cycle power plants. Energy Procedia. 2014;45:1165-74. https://doi.org/10.1016/j.egypro.2014.01.122.

Publisher's Note Springer Nature remains neutral with regard to jurisdictional claims in published maps and institutional affiliations. 